\title{
Processos sustentáveis e conhecimento sobre Química Verde em pequenas empresas do setor de beneficiamento têxtil
}

Sustainable processes and knowledge about Green Chemistry in small enterprises of the textile finishing

\author{
Giovanna Rodrigues Melin \\ Silgia Aparecida da Costa \\ Maurício de Campos Araújo
}

\section{Resumo}

O objetivo deste trabalho é identificar o interesse por processos sustentáveis, conhecimento sobre Química Verde e termos variantes entre profissionais responsáveis pela área produtiva de empresas do segmento de beneficiamento têxtil da Região Metropolitana de São Paulo. Trata-se de estudo exploratório com abordagem quantitativa e qualitativa. Um questionário semiestruturado foi elaborado e enviado a 67 empresas do setor. Utilizou-se de análise estatística descritiva para os dados quantitativos obtidos nas questões fechadas. Para as questões abertas, valeu-se de abordagem qualitativa proposta por Bardin (1977). Os resultados apontam para a necessidade de atenção ao conhecimento de conceitos, inovações e processos químicos alternativos porque os profissionais entrevistados estão pouco atualizados, embora não se reconheçam nessa condição. A legislação ambiental mostrou-se determinante para o envolvimento do setor em práticas mais limpas.

Palavras-chave: Desenvolvimento sustentável, Química Verde; Indústria têxtil.

\begin{abstract}
The aim of this study was to identify the interest in sustainable processes, knowledge about Green Chemistry and variants terms among professionals responsible for the productive area of companies in the segment of textile finishing of the Metropolitan Region of São Paulo. This is an exploratory study with quantitative and qualitative approach. A semistructured questionnaire was developed and sent to 67 companies in the sector. Descriptive statistical analysis was used for quantitative data obtained in the closed questions. For open questions, we used a qualitative approach proposed by Bardin (1977). The results indicate the necessity for attention to the knowledge of concepts, innovations and alternative chemical processes because the professionals interviewees are slightly updated, although it does not recognize this condition. Environmental legislation has proved crucial to the involvement of sector in cleaner practices.
\end{abstract}

Keywords: Sustainable development; Green chemistry; Textile industry.

\section{Introdução}

A indústria têxtil tem importância na economia nacional e mundial. É a segunda maior indústria do mundo, abaixo apenas da indústria de alimentos (ROUETTE, 2000), e abrange os setores de fibras, fiação, tecelagem, malharia, beneficiamento têxtil e confecção. O Brasil é o sexto produtor mundial de têxteis e confeccionados e respondendo por 2,5\% da produção mundial, em 2006 (COSTA e ROCHA, 2009).

Uma característica marcante da indústria têxtil é a descontinuidade do processo produtivo. Embora as etapas se interliguem, não há necessidade de serem realizadas pela mesma empresa, o que favorece a especialização em determinadas etapas do processo produtivo. O setor de beneficiamento têxtil, por exemplo, caracteriza-se pela atuação de empresas de menor porte (SERRA, 2001).

O beneficiamento têxtil abrange diversas etapas de transformação do material têxtil, como tingimento, estamparia e acabamento. Ele proporciona alterações no material têxtil na aparência, capacidade de absorção de água, aumento da resistência, entre outras características (ALCÂNTARA e DALTIN, 1996) e atende mercado em constante transformação como a indústria da moda. Com 
isso, requer alterações regulares nos processos, em especial, na etapa de tingimento. A composição do efluente gerado numa planta pode variar de um dia para o outro e, em certos casos, até no mesmo dia (MOORE e AUSLEY, 2004).

Nesse contexto, o beneficiamento têxtil é a etapa com maior consumo de água e de produtos químicos; apresenta, assim, o maior risco de poluição ambiental, sobretudo de água (ROBINSON et al, 2001; INCE e TEZCANLI, 1999).

Os produtos químicos são responsáveis pelo desempenho e pela variedade dos resultados obtidos no beneficiamento têxtil. Entretanto geram como subproduto elevado volume de efluente tóxico. A complexidade do efluente têxtil dificulta a implantação de sistemas de tratamento nas empresas (MOORE e AUSLEY, 2004).

Os procedimentos que envolvem o uso de substâncias químicas têm potencial para causar impacto negativo no ambiente. Dessa maneira, é essencial que os riscos envolvidos sejam eliminados ou pelo menos reduzidos aos indicadores aceitáveis.

$\mathrm{Na}$ indústria têxtil, os processos sustentáveis podem ser aplicados em diferentes fases da etapa de produção: matérias-primas, equipamentos, produtos químicos utilizados e o tratamento de efluentes.Se o conceito de processo sustentável envolve a ideia de investimentos econômicos viáveis, utilização dos recursos ambientais de modo correto, avanço tecnológico seguro e com justiça social, a Química Verde (QV) pode contribuir com as necessidades humanas e favorecer as transformações atuais, sem prejuízo às novas gerações.A expressão Química Verde, na linguagem corrente, muitas vezes está relacionada aos processos mais limpos, desenvolvimento sustentável e química limpa. Anastas e Warner (1998) definiram Green Chemistry como o projeto, desenvolvimento e implantação de produtos e processos químicos para reduzir ou eliminar o uso de substâncias nocivas à saúde humana e ao meio ambiente. Alguns organismos internacionais, entre eles a Environmental Protection Agency (EPA), adaptaram os conceitos para a aplicação em diferentes segmentos industriais.

Dessa maneira, a QV direciona-se não apenas às consequências causadas pela Química no ambiente, mas antecipa-se e relaciona-se ao desenvolvimento de produtos e aos processos sustentáveis mais limpos.

Nos Estados Unidos, universidades e setores do governo preocupam-se mais com a QV do que outros setores industriais (NAMEROF et al, 2004). Woodhouse e Breyman (2005) argumentam que os químicos, engenheiros e pesquisadores, de modo geral, podem ter envolvimento mais social se refletirem sobre novas maneiras de utilizarem a Química. Apesar dos "profissionais e empresários verdes" ainda serem minoria, com o tempo os inovadores esforços serão institucionalizados e popularizados.

A partir dos anos 2000, alguns autores preocuparam-se em divulgar os conceitos da QV no Brasil (SILVA et al, 2005; LENARDÃO et al, 2003; PRADO, 2003). A Olimpíada de Química São Paulo - 2010, sobre o tema "Química Verde: rumo a produtos e processos sem impacto ambiental", caminhou nesse sentido porque buscou atingir o público jovem de modo direto. No Instituto de Química, da Universidade de São Paulo (USP), por exemplo, desenvolvem-se projetos na Escola de Verão em QV com o propósito de divulgação científica.

O interesse por QV na indústria têxtil, notadamente no setor de beneficiamento têxtil, fundamenta-se por causa das novas diretrizes tecnológicas para o tratamento de efluentes líquidos industriais, produtos químicos não poluidores, redução do consumo de energia e reuso da água.

O objetivo deste trabalho é identificar o conhecimento sobre QV e o interesse por processos sustentáveis entre os profissionais de empresas do segmento de beneficiamento têxtil da Região Metropolitana de São Paulo (RMSP).

\section{Metodologia}

Este trabalho consiste em um estudo exploratório de natureza descritiva, com abordagem quantitativa e qualitativa. A finalidade de trabalho exploratório é estudar e criar conhecimento da realidade presente. Busca esclarecer conceitos, estabelecer prioridades para futuras pesquisas, obter informações sobre possibilidades práticas de realização de pesquisa em situações de vida real e apresentar recenseamento de problemas considerados urgentes por pessoas que trabalham em determinado campo (SELLTIZ et al, 1975).

Foram contatadas 67 empresas do setor de beneficiamento têxtil de pequeno, médio e grande porte em 19 cidades da RMSP. O contato foi realizado por telefone e por e-mail. Do total das organizações, sete se dispuseram a participar desta pesquisa.

As empresas foram contatadas três vezes pelo mesmo pesquisador e os motivos observados para o não interesse em participar foram: desconhecimento dos procedimentos acadêmicos, 
intolerância em relação ao tempo gasto para atender os pesquisadores e responder o questionário, dúvidas quanto à possibilidade de espionagem e revelação de informações sobre a empresa.

Foram entrevistados profissionais responsáveis pela área produtiva e os dados foram obtidos por intermédio de questionário semiestruturado aplicado entre abril e junho de 2009.

O questionário compreendeu quatro áreas de análise:

1) Caracterização da empresa; 2) Conhecimentos sobre Green Chemistry (Química Verde) e termos variantes; 3) Procedimentos para redução do consumo de água e energia; 4) Inovação de processos e produtos químicos alternativos.

Para a análise dos dados, utilizou-se o tratamento estatístico por meio de análise descritiva e distribuição de frequências obtidas das questões fechadas (análise quantitativa).

Empregou-se abordagem qualitativa proposta por Bardin (1977) para as questões abertas porque se buscou aprofundar a realidade, captar significados, valores, motivos, atitudes e crenças.

\section{Resultados e Discussão}

$\mathrm{Na}$ Tabela 1, as características das organizações podem ser observadas. Predominam empresas que atuam no mercado há mais de 11 anos; a quantidade de funcionários oscila de 10 a 58 e localizam-se em diferentes cidades da RMSP.

\begin{tabular}{c|c}
\hline NUMERO DE FUNCIONARIOS & FREQUENCIA \\
\hline Até 30 & 5 \\
\hline $31-60$ & 2 \\
\hline 61 ou mais & 0 \\
\hline
\end{tabular}

TEMPO DE ATUAÇÃO NO MERCADO (EM ANOS)

\begin{tabular}{c|c}
\hline Até 10 & 1 \\
\hline $11-20$ & 3 \\
\hline $21-30$ & 2 \\
\hline 31 ou mais LOCALIZAÇÃo & 1 \\
\hline \multicolumn{1}{c|}{ São Paulo } & 2 \\
\hline Guarulhos & 2 \\
\hline Caieiras & 1 \\
\hline Diadema & 1 \\
\hline Santo André & 1 \\
\hline Tabela 1 - Características das organizações \\
\hline
\end{tabular}

A classificação quanto ao porte da empresa seguiu a livre declaração do entrevistado. Optou-se por não identificar o porte da empresa nem por faturamento nem por volume de produção. Todas as empresas que se dispuseram a participar da pesquisa se declararam de pequeno porte.

De acordo com a Agência Brasileira de Desenvolvimento Industrial (2008) as empresas de micro e pequeno porte do setor têxtil são responsáveis por 850 mil postos de trabalhos.

Para o Serviço Brasileiro de Apoio às Micro e Pequenas Empresas (SEBRAE, 2011), empresas com mais de cinco anos de atuação no mercado ultrapassaram o período considerado crítico. $O$ resultado mostra que neste estudo todas as organizações entrevistadas transpuseram esse período (tabela 1).

Na tabela 2 verificou-se que os termos: Química Verde, Química Autossustentável e Green Chemistry são desconhecidos pelos profissionais que atuam na área produtiva. Química Limpa é conhecida por dois profissionais.

\begin{tabular}{c|c|c|c}
\hline & CONHECE & DESCONHECE & TOTAL \\
\hline Química Verde & 0 & 7 & 7 \\
\hline Química Limpa & 2 & 5 & 7 \\
\hline Química Autossustentável & 0 & 7 & 7 \\
\hline Green Chemistry & 0 & 7 & 7 \\
\hline
\end{tabular}

Tabela 2 - Distribuição das respostas quanto ao conhecimento sobre QV e termos variantes

Fonte: Elaboração própria 
$\mathrm{Na}$ literatura encontram-se relatos preocupantes quanto ao conhecimento dos químicos e dos estudantes de Química sobre QV de modo geral (LEAL e MARQUES, 2008). No entanto, não foram encontrados estudos sobre o conhecimento ou a divulgação de QV no segmento do beneficiamento têxtil, nem na indústria têxtil.

O conhecimento pode desenvolver a consciência verde, formar profissionais ainda mais responsáveis e favorecer a qualidade de vida. Lago et al. (2005) destacam a importância do empreendedorismo e da formação de empreendedores tecnológicos na área de Química. Para os autores, o empreendedorismo em Química pode ser aplicado a qualquer outra área da ciência e tecnologia. A ciência e o conhecimento desempenham papel fundamental para o desenvolvimento da sociedade.

Leal e Marques (2008) analisaram a grade curricular de cinco cursos de licenciatura em Química no sul do Brasil. Verificaram que os cursos desconsideram a problemática ambiental. Quando apreciam é de modo parcial e sob perspectiva da Química Ambiental, sem contemplar a QV.

Ferreira et al. (2007), Chen e Burns (2006) e Kunz et al. (2002) consideram que a globalização e a escassez de alguns recursos naturais estimulam a crescente busca industrial por processos e tecnologias ambientalmente corretas. Nesse sentido, intensifica-se a necessidade das indústrias se adaptarem às tecnologias mais limpas e às novas exigências do consumidor que cada vez mais se preocupa em adquirir produtos que respeitem o meio ambiente em diferentes fases da produção.

O conhecimento dos profissionais da cadeia têxtil da RMSP sobre QV pode estimular processos sustentáveis no setor e proporcionar oportunidade de desenvolver o pensamento crítico e a compreensão das vantagens decorrentes da alternativa verde.

De acordo com Ghosh et al. (2004), ao se aprender como equilibrar as limitações dos recursos naturais e prevenir a poluição com o crescimento econômico, a QV será a ciência central da sustentabilidade.

Os químicos desempenham função fundamental para mudar a imagem da opinião pública acerca da Química. Os avanços obtidos em QV podem contribuir para os empresários modificarem o comportamento em relação ao meio ambiente e, a sociedade, em relação à Química (SANTOS, 2006).

Com base na tabela 3, é possível observar que as medidas para redução do consumo de água, reutilização e tratamento da água antes do descarte e a redução do consumo de energia (elétrica e térmica) são parcialmente praticadas pelas empresas entrevistadas.

\begin{tabular}{c|c|c|c}
\hline & PRATICA & NÃO PRATICA & TOTAL \\
\hline Redução do consumo de água & 4 & 3 & 7 \\
\hline Reutilização da água & 3 & 4 & 7 \\
\hline Tratamento da água antes do descarte & 4 & 3 & 7 \\
\hline Redução do consumo de energia elétrica & 5 & 2 & 7 \\
\hline Redução do consumo de energia térmica & 2 & 5 & 7 \\
\hline
\end{tabular}

Tabela 3 - Distribuição das respostas quanto às medidas para redução e reutilização do consumo de água e redução do consumo de energia (elétrica e térmica) Fonte: Elaboração própria

Verificaram-se os seguintes comentários sobre a reutilização da água:

"Armazenamos a água usada em lavagens de cores claras e reaproveitamos nas cores mais escuras. É economia mesmo!" (Empresa 5).

"Utilizamos processos com relação de banho mais curto" (Empresa 7).

Se os que praticam as medidas enfatizam a preocupação financeira, sem o cuidado com o meio ambiente, os que responderam que não as praticam ofereceram respostas evasivas.

A água é um dos principais insumos do setor de beneficiamento têxtil. De acordo com Ozturk et al. (2009), o consumo de água pode variar de 70 a $250 \mathrm{~L} / \mathrm{kg}$ de tecido, de acordo com a técnica utilizada.

Estudo realizado em 10 empresas de beneficiamento têxtil de Santa Catarina verificou que as empresas usam estratégias ou tendências com base em práticas limpas, para reduzir o consumo de água e de energia (COSTA e MARTINS, 1997).

Em outro estudo, Ferreira et al. (2009) analisaram 23 empresas que trabalham com tingimento em Brusque, Santa Catarina. Observaram que 16 reutilizavam a água e, em 21 delas, há tratamento antes do descarte. Neste estudo, todos os funcionários das empresas entrevistadas trabalham com tingimento e quatro delas tratam a água antes de descartá-la (tabela 3).

Se a filosofia verde estivesse mais presente nas empresas de setor de beneficiamento têxtil da RMSP, a questão ecológica estaria, talvez, aliada às questões econômicas. Dessa maneira, favoreceria ainda mais a redução e a reutilização de água, como ocorre, por exemplo, em algumas 
organizações do mesmo segmento nos estados de Santa Catarina, Espírito Santo e Mato Grosso do Sul.

Na tabela 4, verificou-se que apenas uma empresa possui funcionário ou setor responsável por desenvolver processos sustentáveis. Ela emprega 15 funcionários e atua no mercado há 20 anos. As duas empresas que buscam produtos alternativos mais limpos têm menos de 30 funcionários e 0 período em que estão no mercado é de 21-30 anos.

Notou-se ainda preocupação com o consumo de produtos, uma vez que quatro empresas têm métodos para evitar desperdícios de produtos. Entretanto, apenas duas substituem ou eliminam substâncias que agridem o meio ambiente e quatro consideram que investir em técnicas sustentáveis requer alto custo. É provável que a dificuldade financeira de investir em tecnologias sustentáveis também justifique a não aquisição de novos equipamentos nos últimos dois anos. Da mesma maneira, rotulagem ou certificação não parecem ser prioridades para as empresas entrevistadas.

\begin{tabular}{|c|c|c|c|c|}
\hline & SIM & NÃO & $\begin{array}{l}\text { NÃO TEM } \\
\text { INTERESSE }\end{array}$ & TOTAL \\
\hline $\begin{array}{c}\text { Funcionário ou setor responsável por desenvolver } \\
\text { processos sustentáveis }\end{array}$ & 1 & 6 & - & 7 \\
\hline Pesquisam no mercado produtos alternativos mais limpos & 2 & 5 & - & 7 \\
\hline Eliminação de desperdícios de produtos & 4 & 2 & 1 & 7 \\
\hline $\begin{array}{l}\text { Substituição ou eliminação de substâncias nocivas ao meio } \\
\text { ambiente }\end{array}$ & 2 & 4 & 1 & 7 \\
\hline Investimento em técnicas sustentáveis tem alto custo & 4 & 1 & 2 & 7 \\
\hline Aquisição de novos equipamentos nos últimos 2 anos & 0 & 7 & - & 7 \\
\hline Posse de rotulagem ou certificação & 0 & 7 & - & 7 \\
\hline
\end{tabular}

Tabela 4 - Distribuição das respostas quanto à afirmação ou negação para inovar processos e buscar produtos químicos alternativos

Fonte: Elaboração própria

Técnicas sustentáveis geram alto custo para a empresa, conforme algumas declarações abaixo:

"Não temos como pagar... o custo é altíssimo" (Empresa 1).

"Dizem que o custo é alto. É o que ouço dizer" (Empresa 3).

Fresner (2004) comenta que convencer a administração de pequenas e médias empresas da importância e do potencial de ações ambientais é a chave para ativar a melhoria de aspectos ambientais de pequenos e médios negócios.

As condutas ambientais em indústrias têxteis de pequeno e de grande porte foram observadas por Abreu et al. (2008). Se por um lado, as empresas de grande porte percebem os investimentos ambientais como importantes para a competitividade, por outro, as empresas de pequeno porte enfatizam a adequação à legislação e à qualidade das emissões, para não serem multadas, e evitam desperdícios, por causa do lucro.

Importante descoberta deste estudo é que a legislação interfere na conduta ambiental dos profissionais que atuam nas organizações, em especial no descarte de água, conforme se verifica abaixo.

"Fazemos análises periódicas que apontam que não há necessidade de processos de tratamento antes do descarte. Estamos dentro dos limites permitidos pela legislação" (Empresa 2).

Observa-se que os profissionais do segmento da indústria têxtil pesquisado preocupam-se em respeitar os limites determinados pela legislação. Kunz et al. (2002) afirmam que o maior desafio das empresas é adequar-se à legislação de descarte de efluente líquido por causa da variedade do efluente gerado pelo setor.

O efluente têxtil em particular é sazonal, sofre mudanças constantes em virtude do substrato utilizado, dos produtos químicos e da demanda o que dificulta seu tratamento.

A legislação nacional sobre o descarte de efluentes líquidos não apresenta restrições quanto à cor do efluente (TUNUSSI e ALÉM SOBRINHO, 2003)

A legislação ambiental brasileira é complexa. De um Estado para outro os parâmetros são muito diferentes. Delatorre Junior e Morita (2007) ressaltam que a legislação paulista é de 1980. Dessa maneira, precisa se atualizada. Consideram que determinados limites podem estar restritivos e outros permissivos.

Namerof et al. (2004) consideram que a concessão de mais de 3.200 patentes relacionadas à QV entre 1983 a 2001, nos Estados Unidos, coincidem com a adoção de leis ambientais mais rígidas. 
Órgãos governamentais e não governamentais empenham-se em desenvolver publicações e manuais que deem suporte a indústria têxtil na implantação de processos que agridam menos o meio ambiente. Exemplo dessa iniciativa é o Best Management Practices for Pollution Prevention in the Textile Industry, manual desenvolvido pela EPA (1996).

A partir do momento em que a indústria têxtil, em especial o setor de beneficiamento têxtil, incorporar as tecnologias mais limpas aos diferentes processos, o segmento poderá transmitir à sociedade mensagem positiva de desenvolvimento sustentável.

Neste trabalho, deparou-se com muita dificuldade para estimular os profissionais das organizações a responderem o questionário, o que pode revelar indiferença em relação à pesquisa científica. Quanto a isso, talvez os motivos sejam a falta de parcerias entre o setor e a universidade e de estudos sobre a indústria têxtil da RMSP. O que parece não ocorrer na indústria têxtil do estado de Santa Catarina, por exemplo, em que as pesquisas científicas na área estão mais avançadas.

\section{Considerações finais}

O conhecimento dos profissionais entrevistados que atuam nas pequenas empresas do setor de beneficiamento têxtil da RMSP sobre QV ainda é escasso e são poucos os processos mais limpos. $\mathrm{O}$ interesse por processos sustentáveis ainda tem pouca importância para os profissionais do setor analisado.

Se a QV busca prevenir para evitar futuros reparos, observou-se que os profissionais que atuam no segmento estudado demonstraram pouca conscientização quanto à prevenção. As preocupações estão relacionadas à adequação â legislação vigente para evitar multas e a economia de produtos, energia e água apenas com valor econômico.

Os profissionais responsáveis pelos processos de produção têxtil que foram entrevistados não estão devidamente atualizados e demonstraram-se pouco comprometidos com as novas tecnologias. As medidas para minimizar os impactos ambientais causados pelo setor ainda são tímidas.

Todavia, nem a quantidade nem o porte das organizações em que trabalham os profissionais que se dispuseram a responder o questionário representam o setor de beneficiamento têxtil da RMSP. O porte da empresa pode ter interferido no nível de conhecimento dos profissionais sobre QV e na prática de processos sustentáveis.

Conforme os conceitos e inovações tecnológicas forem mais divulgados, talvez ocorra mais conscientização dos estudantes de Química, pesquisadores em geral, empresários e toda a sociedade seja atingida. Ainda que o público em geral não domine seus conceitos e mecanismos, poderá se interessar em saber como os produtos que consome foram produzidos e, quem sabe, passe a exigir da cadeia produtiva processos cada vez mais limpos, como atualmente começam a florescer.

Acredita-se que outros estudos possam dar continuidade a este trabalho porque se ignora, até o momento, pesquisa sobre conhecimento dos profissionais do segmento de beneficiamento têxtil da RMSP, quanto à QV, aos processos sustentáveis e as inovações tecnológicas.

\section{Agradecimentos}

Ao Santander/PIBIC-USP pelo incentivo financeiro.

Ao Pedro Reiz, pelo acompanhamento e análise crítica desta produção.

\section{Referências}

AGÊNCIA BRASILEIRA DE DESENVOLVIMENTO INDUSTRIAL (ABDI). Panorama setorial têxtil e confecção. Agência Brasileira de Desenvolvimento Industrial, Centro de Gestão e Estudos Estratégicos. Brasília: Associação Brasileira de Desenvolvimento Industrial, 2008.

ABREU, M. C. S., SILVA FILHO, J. C. L.; OLIVEIRA, B. C.; HOLANDA JÚNIOR, F.L. Perfis estratégicos de conduta social e ambiental: estudos na indústria têxtil nordestina. Gestão \& Produção, 2008:15(1); 159-72.

ALCÂNTARA, M. R.; DALTIN, D. A química no processamento têxtil. Química Nova, 1996:19(3); 32030.

ANASTAS, P. T.; WARNER, J. C. Green chemistry: theory and practice. New York, Oxford, 1998. 
BARDIN, L. Análise de conteúdo. Tradução por: Luís Antero Reto e Augusto Pinheiro. Lisboa: Edições 70, 1977. Tradução de: L'Analyse de contenu.

CHEN, H. L.; BURNS, L. D. Environmental analysis of textile products. Clothing and Textile Research Journal, 2006:24(3);248-61.

COSTA, R. H. R.; MARTINS, G. B. H. Práticas limpas aplicadas as indústrias têxteis do Estado de Santa Catarina. In: 19ํㅡㄹ Congresso Brasileiro de Engenharia Sanitária e Ambiental, 1997. Disponível em: http://www.bvsde.paho.org/bvsacd/abes97/practicas.pdf. Acesso em: 30 out. 2010.

COSTA, A. C. R.; ROCHA, E. R. P. Panorama da cadeia produtiva têxtil e de confecções e a questão da inovação. BNDES Setorial, Rio de Janeiro, 2009:29;159-202.

DELATORRE JUNIOR, I.; MORITA, D. M. Avaliação da eficácia dos critérios de recebimento de efluentes não domésticos em sistemas de coleta e transporte de esgotos sanitários em São Paulo. Eng. Sanit. Ambient, 2007:12(1);62-70.

ENVIRONMENTAL PROTECTION AGENCY (EPA) Best management practices for pollution prevention in the textile industry. 1996 (296 telas). Disponível em: http://www.p2pays.org/ref/02/01099/0109900.pdf. Acesso em: 10 fev. 2011.

FERREIRA, D. D. M.; KELLER, J; SILVA, L. E. A utilização da água pela indústria têxtil: uma pesquisa no município de Brusque, SC. Inter Science Place, 2009:2(8);1-19.

FERREIRA, O. P.; ALVES, O. L.; MACEDO, J. S.; GIMENEZ, I. F.; BARRETO, L.S. Ecomateriais: desenvolvimento e aplicação de materiais porosos funcionais para proteção ambiental. Química Nova, 2007:30(2);464-67

FRESNER, J. Small and medium sized enterprises and experiences with environmental management. Introduction. Journal of Cleaner Production, 2004(12);545-47.

GHOSH, A.; GUPTA, S. S.; BARTOS, M. J.; HANGUN, Y.; VUOCOLO, L. D.; STEINHOFF B. A. et al. Green chemistry: sustaining e high-technology civilization. Pure Appl Chem, 2004:73(1);113-8.

INCE, N. H.; TEZCANLI, G. Treatability of textile dye-bath effluents by advanced oxidation: preparation fou reuse. Wat Sci Tech, 1999:40(1);183-190.

KUNZ, A.; PERALTA-ZAMORA, P.; MORAES, S. G.; DURAN, N. Novas tendências no tratamento de efluentes têxteis. Química Nova, 2002:25(1);78-82.

LAGO, M. H. A. R. M.; OLIVEIRA, L. C. A.; CABRAL, P. R. M.; CHENG, L. C.; FILION, L. J. Estimulo ao empreendedorismo nos cursos de química: formando químicos empreendedores. Química Nova, 2005:28(Supl);18-25.

LEAL, A. L.; MARQUES, C. A. O conhecimento químico e a questão ambiental na formação docente. Química Nova na Escola, 2008:29;30.

LENARDÃO, E. J.; FREITAG, R. A.; DABDOUB, M. J.; BATISTA, A. C. F.; SILVEIRA, C. C. "Green chemistry": os 12 princípios da química verde e sua inserção nas atividades de ensino e pesquisa. Química Nova, 2003:26(1);123-29.

MOORE, S. B.; AUSLEY, L. W. Systems thinking and green chemistry in the textile industry: concepts, technologies and benefits. Journal of Cleaner Production, 2004:12;585-601.

NAMEROFF, T. J.; GARANT, R. J.; ALBERT, M. B. Adoption of green chemistry: an analysis based on US patents. Research Policy, 2004:33;959-74.

OZTURK, E.; YETIS, U.; DILEK, F. B.; DEMIRER, G.N. A chemical substituition study for a wet processing textile mill in Turkey. Jounal of Cleaner Production, 2009: 17;239-47.

PRADO, A. G. S. Química verde, os desafios do novo milênio. Química Nova, 2003:26(5);738-44. 
ROBINSON, T.; MCMULLAN, G.; MARCHANT, R.; NIGAM, P. Remediation of dyes in textile effluent: a critical review on current treatment technologies with a proposed alternative. Bioresource Technology, 2001:77;247-55.

ROUETTE, H. K. Encyclopedia of textile finishing. Springer, 2000. 1 CD-ROM.

SANTOS, W. L. P. Letramento em química, educação planetária e inclusão social. Química Nova, 2006:29(3);611-20.

SERVIÇO BRASILEIRO DE APOIO ÀS MICRO E PEQUENAS EMPRESAS. SEBRAE-SP e FAEDPYME apresentam estudo feito em 20 países. SEBRAE, São Paulo, 2011. Disponível em:

$<$ http://www.sebraesp.com.br/PortalSebraeSP/Noticias/Noticias/Multissetorial/Paginas/sebraesp_e_fa edpyme_apresentam_estudo_feito_em_20_paises.aspx>. Acesso em: 15 mai. 2011.

SELLTIZ, C.; JAHODA, M.; DEUTSCH, M.; COOK, S. W. Tradução por: Dante Moreira Leite. Métodos de pesquisa nas relações sociais. São Paulo: EPU/EDUSP, 1975. Tradução de: Research methodes in social relations, p.60.

SERRA, N. O desempenho das MPEs no setor têxtil-confecção. São Paulo: Serviço de Apoio às Micro e Pequenas Empresas de São Paulo (SEBRAS-SP) e Instituto de Pesquisas Tecnológicas (IPT), jul., 2001. p.5-6.

SILVA, F. M.; LACERDA, P. S. B.; JONES JUNIOR, J. Desenvolvimento sustentável e química verde. Química Nova, 2005:28(1);103-10.

TUNUSSI, J. L.; ALEM SOBRINHO, P. Remoção de Cor e Nitrificação de Efluentes de Tinturaria Têxtil Através de Processos Biológicos Anaeróbio-Aeróbio. 2003. Disponível em: <http://www.bvsde.paho.org/bvsaidis/mexico26/ii-135.pdf>. Acesso em: 15 dez. 2010.

WOODHOUSE, E.; BREYMAN, S. Green chemistry as social movement? Science, Technology \& Human Values, 2005:30(2);199-222. 